\title{
Understanding parasite strategies
}

\section{Roger Jovani}

Department of Applied Biology, Estación Bioló gica de Doñana, Consejo Superior de Investigaciones Científicas, Avda. M ${ }^{a}$ Luisa s/n, 41013 Sevilla, Spain

Fré dé ric Thomas et al. [1] state in a recent stimulating article that the environmental perception of parasites and how they use this information on their own have been undervalued and needs further research. Moreover, they suggest that although generalizations from one parasite species to another must be done with caution, "it would be interesting to determine whether different parasite species experiencing similar ecological pressures evolve perception of similar signals (i.e. evolutionary convergence)”. Most

Corresponding author: Roger Jovani (jovani@ebd.csic.es). free-living individual organisms are the habitat for different species of symbionts with which they hold different kinds of relationships from parasitism to mutualism. Thus, a further step could be done on the perspectives pointed out by Thomas et al. [1] - by expanding our range of potential study species to all symbiont organisms living in host-parasite systems under investigation.

Recent advances on the behaviour of mites and lice living on the feathers of birds could illustrate this issue. Feather mites and lice have very low life expectancies when 
not on a bird and, consequently, feather moult constitutes a high risk of mortality. Interestingly, feather mites and lice have evolved different strategies to counteract this environmental pressure: feather mites living on the wing of birds evade the feathers that will fall down soon [2], and many lice individuals congregate into the sheath that encases developing feathers, thus ensuring that they will be on a feather that will not be moulted soon [3]. Feather mites have been suggested to use the vibration of feathers that are close to falling down as a cue for leaving them [2], but nothing has been hypothesized for this lice behaviour. Do lice perceive the start of the moult of birds by the same cue as feather mites? Is the different escape behaviour the consequence of different ways of perceiving the start of moult? Is it some interaction between feather mites and lice behind the use of different strategies to avoid the moult?

Lice are bird ectoparasites that eat the bird's feathers, which can lower the survival expectancies of birds because of a loss of the thermal insulative effectiveness of their plumage [4], and reduce sexual attractiveness of males in front of potential mates [5]. Feather mites have been also used as the 'parasite variable' in some studies of parasitemediated sexual selection [6]. Although controversial, current empirical studies on feather mites point to the direction that they are commensals or even mutualists of birds [7]. This agrees with the observation that birds with thousands of feather mites do not show any apparent injury and that feather mites eat the oil that birds spread from the uropygial gland, consuming, at the same time, feather-degrading bacteria and fungi, thus acting as the 'feather sweepers' of birds [7]. This example of feather mites and lice shows that parasite and non-parasite symbionts can evolve behavioural responses to same host-mediated environmental pressures; hence, comparison of their behaviours could be performed easily and could improve the understanding of both parasite and nonparasite symbionts at the same time. Thus, parasitologists face the dilemma of abandoning the study of feather mites and other non-parasitic symbionts, or they can seize this opportunity for understanding bird -lice and other host parasite interactions by integrating non-parasite symbionts into the study. I believe that the comparative study of parasite and non-parasite symbionts that share the same host represents a useful tool for understanding parasite strategies.

\section{References}

1 Thomas, F. et al. (2002) Understanding parasite strategies: a statedependent approach? Trends Parasitol. 18, 387-390

2 Jovani, R. and Serrano, D. (2001) Feather mites (Astigmata) avoid moulting wing feathers of passerine birds. Anim. Behav. 62, 723-727

3 Moyer, B.R. et al. (2002) Impact of feather molt on ectoparasites: looks can be deceiving. Oecologia 131, $203-210$

4 Clayton, D.H. et al. (1999) Reciprocal natural selection on host - parasite phenotypes. Am. Nat. 154, $261-270$

5 Clayton, D.H. (1990) Mate choice in experimentally parasitized rock doves: lousy males lose. Am. Zool. 30, 251-262

6 Thompson, C.W. et al. (1997) High parasite load in house finches (Carpodacus mexicanus) is correlated with reduced expression of a sexually selected trait. Am. Nat. 149, $270-294$

7 Blanco, G. et al. (2001) Feather mites on birds: costs of parasitism or conditional outcomes? J. Avian Biol. 32, 271-274

\section{Understanding parasite strategies}

Response from Sam P. Brown and Frédéric Thomas

\section{Sam P. Brown ${ }^{1}$ and Frédéric Thomas ${ }^{2}$}

${ }^{1}$ Institut des Sciences de l'Evolution, Université Montpellier 2, Place Eugène Bataillon, 34095 Montpellier Cedex 05, France ${ }^{2}$ Centre d $\mathrm{d}^{0}$ Etude sur le Polymorphisme des Micro-organismes, Unité Mixte de Recherches Centre National de la Recherche Scientique, Institut de Recherche pour le Développement 9926, Equipe: Evolution des Systèmes Symbiotiques, 911 Avenue Agropolis, BP 5045 34032, Montpellier Cedex 1, France

We agree with Roger Jovani that it is important to search for insights into parasite biology by using a comparative approach. Jovani draws particular attention to the possibility of comparisons among a broader range of symbionts, crossing the parasite-mutualist divide. This highlights certain questions that were overlooked in our recent article on parasite plasticity [1]. We considered that parasites would have reliable access to cues relating to the internal and external host environment, allowing an appropriate adjustment of parasite behaviour. However, by considering that the relationship between host and symbiont could vary from an antagonistic (parasites) to a cooperative (mutualists) one, we see that the host will not necessarily be a passive player, but could actively try to suppress, manipulate or enhance the signals read by its symbiotic occupants.

The evolutionary study of biological signals is a large and dynamic field of research [2], yet, to our knowledge, no studies directly involve parasites (although they often figure as bit players in models of sexually selected signalling displays, e.g. Ref. [3]). We doubt that this oversight is due to a lack of empirical examples, and suggest that experimental work in this direction would be well rewarded. Looking across parasitic and mutualistic symbionts, what range of behaviour might we envisage? When symbiont plasticity spans a mutualistic range of behaviours, we might expect hosts to enhance 'helpful' signals to their symbionts, for instance, in the case of 